\title{
PROJETO DE EXTENSÃO SAÚDE PÚBLICA EM AÇÃO E SUA ATUAÇÃO DURANTE A PANDEMIA OCASIONADA PELA COVID-19
}

\section{THE OUTREACH PROJECT "PUBLIC HEALTH IN ACTION" AND ITS DEVELOPMENT DURING COVID 19 PANDEMIC}

\author{
Ana Paula Zaikievicz Azevedo* \\ ORCID: https://orcid.org/0000-0001-6737-9404 \\ Magyda Arabia Araji Dahroug Moussa** \\ ORCID: https://orcid.org/0000-0002-2946-2087 \\ Paula Helena Santa Rita*** \\ ORCID: https://orcid.org/0000-0001-5822-0266
}

\section{Resumo}

Este trabalho objetiva compartilhar as experiências desenvolvidas em um projeto de extensão interdisciplinar, envolvendo docentes e acadêmicos de diferentes áreas do conhecimento, da Universidade Católica Dom Bosco, cidade de Campo Grande, capital do Mato Grosso do Sul, especialmente no que concerne ao trabalho desenvolvido pelo projeto durante o ano de 2020, em meio a pandemia ocasionada pela COVID-19. O projeto denomina-se "Saúde Pública em Ação" e tem como principal objetivo compartilhar com a sociedade conhecimentos acerca da temática de saúde única através de ações diversificadas, atendendo distintos públicos, com diferentes faixas etárias. O desenvolvimento do projeto tem possibilitado ampliar a formação acadêmica e pessoal dos acadêmicos e docentes envolvidos nas ações, além de contribuir com as comunidades e instituições atendidas, possibilitando maiores informações e conhecimentos sobre a saúde humana, animal e cuidados com o meio ambiente, além de oportunizar uma rica troca de saberes e culturas entre os envolvidos.

Palavras-chaves: Extensão universitária; Interdisciplinaridade; Pandemia

Data recebimento: $22 / 05 / 2021$

Data de aceite: $02 / 09 / 2021$

\begin{abstract}
This study aims to share the experiences of the interdisciplinary outreach project "Public Health in Action" carried out by professors and undergraduate students from different areas at Dom Bosco Catholic University, located in Campo Grande, the capital of Mato Grosso do Sul, especially with regard to the activities developed in 2020, in the midst of COVID-19 pandemic. The main purpose of the project is to share with society knowledge about the theme One Health through actions developed with people from different groups and ages. The development of the project has made it possible to expand the academic and personal education of the students and professors, to contribute to the communities and institutions, and to provide more information and knowledge about human and animal health as well as environmental care. It also provides opportunities for exchanging knowledge and cultures between those involved.
\end{abstract}

Keywords: University Extension; Interdisciplinarity; Pandemic.

* Professora da Universidade Católica Dom Bosco (UCDB), Campo Grande - MS, Brasil. Email: 4599@ucdb.br

** Professora da Universidade Católica Dom Bosco (UCDB), Campo Grande - MS, Brasil. Email: magyda@ucdb.br

*** Professora da Universidade Católica Dom Bosco (UCDB), Campo Grande - MS, Brasil. Email: paulabiovet@ucdb.br 


\section{Introdução}

Este texto tem como principal objetivo discutir acerca da importância da extensão universitária para a sociedade, bem como contextualizar as ações realizadas pelo projeto de extensão "Saúde Pública em Ação", especialmente durante o período de distanciamento social, ocasionado pela disseminação do vírus COVID-19, no ano de 2020.

Para melhor organização, o trabalho está organizado em três seções. Na primeira seção, contextualizamos a extensão universitária como um dos tripés que compõem o trabalho desenvolvido pela Universidade Católica Dom Bosco (UCDB), buscando, assim, garantir que os conhecimentos produzidos no âmbito acadêmico sejam compartilhados com a sociedade.

Na segunda seção, apresentamos o projeto de extensão "Saúde Pública em Ação" e as ações desenvolvidas pela equipe que o integram.

Na terceira seção, trazemos algumas considerações acerca do trabalho e dos resultados atingidos por meio das ações desenvolvidas pelo projeto durante o ano de 2020, em meio à pandemia e à necessidade de distanciamento social. E para finalizar, na quarta seção, tecemos algumas considerações finais sobre o trabalho desenvolvido.

\section{Contextualizando a extensão universitária na Universidade Católica Dom Bosco (UCDB)}

Atualmente, a universidade brasileira organiza-se a partir de três principais aspectos: ensino, pesquisa e extensão. Essa organização está legitimada pela Constituição da República Federativa do Brasil (1988), através de seu artigo 207, o qual estabelece que. "As universidades gozam de autonomia didático-científica, administrativa e de gestão financeira e patrimonial, e obedecerão ao princípio de indissociabilidade entre ensino, pesquisa e extensão" (BRASIL, 1988).

Nessa ótica, pode-se compreender que o desafio da universidade na contemporaneidade é legitimar o desenvolvimento de um trabalho que não apenas contemple as características do ensino, da pesquisa e da extensão, mas que possibilite a estas três vertentes atuarem coletivamente e colaborativamente, oportunizando que os conhecimentos produzidos e ressignificados no âmbito acadêmico sejam compartilhados com a sociedade. 
Severino (2007, p. 24) considera que

\begin{abstract}
É assim que a própria extensão universitária deve ser entendida como o processo que articula o ensino e a pesquisa, enquanto interagem conjuntamente, criando um vínculo fecundante entre a Universidade e a sociedade, no sentido de levar a esta a contribuição do conhecimento para sua transformação. Ao mesmo tempo que a extensão, enquanto ligada ao ensino, enriquece o processo pedagógico, ao envolver docentes, alunos e comunidade num movimento comum de aprendizagem, enriquece o processo político ao se relacionar com a pesquisa, dando alcance à produção do conhecimento.
\end{abstract}

A partir disso, faz-se necessário compreender que a extensão universitária é considerada atualmente um importante canal de comunicação entre a universidade e a sociedade. Por meio dela, professores e acadêmicos têm a oportunidade de dialogar com os segmentos sociais, produzindo novos saberes, colocando em prática conhecimentos obtidos teoricamente e, consequentemente, contribuir para a ascensão social das comunidades atendidas.

$\mathrm{Na}$ Universidade Católica Dom Bosco (UCDB), a extensão universitária se desenvolve por meio de programas institucionais, laboratórios e projetos de extensão. No que concerne ao desenvolvimento dos projetos de extensão, vale ressaltar que, no ano de 2020 , a universidade possuía 18 projetos de extensão em desenvolvimento.

Os projetos de extensão, na UCDB, são selecionados via processo seletivo, o qual segue critérios estabelecidos por um edital de seleção elaborado e monitorado pela Pró-Reitoria de Graduação e Extensão e pelo Comitê de Extensão da própria universidade. Todos os projetos inscritos passam por um processo avaliativo, composto por avaliadores internos da Universidade e $a h$ doc. O período de duração de cada projeto é de 1 ano, podendo ser renovado por igual período, através de novos processos seletivos.

De acordo com a Política de Extensão da UCDB, os projetos de extensão precisam ser interdisciplinares e desenvolverem-se de modo a afirmar o compromisso da instituição com "a produção do conhecimento e a superação das desigualdades sociais, aliando as demandas socialmente existentes e os resultados do trabalho acadêmico, atendendo um dos princípios do Plano Nacional de Extensão" (UNIVERSIDADE CATÓLICA DOM BOSCO, 2018, p. 11).

Nessa mesma perspectiva, Freire (1987) ressalta a interdisciplinaridade como o processo metodológico de construção do saber pelo indivíduo, baseando-se na sua relação com o contexto, envolvendo a sua realidade, sua cultura, e pela caracterização de dois movimentos dialéticos: a problematização da situação pela qual se desvela a realidade e a sistematização dos conhecimentos de forma integrada. 
Para Síveres (2013), a extensão universitária precisa ser destacada como uma diretriz institucional nas universidades, oportunizando o desenvolvimento de

[...] um processo mediador de construção do conhecimento e uma atividade que aponta para a finalidade do percurso da aprendizagem, qualificando o valor epistemológico, ético e político da instituição, que deve ser vivenciado cotidianamente pelos sujeitos acadêmicos e comunitários, pelos processos instituídos e instituintes, e pelos resultados individuais e coletivos (SÍVERES, 2013, p. 20).

Ou seja, a extensão é um campo do conhecimento que não se realiza individualmente, mas se efetiva a partir da colaboração entre os sujeitos, em especial entre professores, acadêmicos e componentes das comunidades externas da universidade. A partir dessa interação, ambos têm a oportunidade de aprender, compartilhar saberes e contribuir para uma sociedade com mais igualdade de direitos e acesso a informações, especialmente daqueles que, muitas vezes, não têm acesso e condições de frequentar um banco acadêmico e ou de acessarem conhecimentos científicos, que podem contribuir com suas melhores condições de vida.

\section{Caracterização do Projeto de Extensão "Saúde Pública em Ação"}

O Projeto de Extensão Saúde Pública em Ação, em sua atual configuração, existe desde o ano de 2019. Iniciou-se em 2014, com uma característica diferente e foi, ao longo dos anos, passando por algumas reformulações, tanto na organização de sua proposta de atuação quanto na composição da equipe. Tais mudanças se fizeram necessárias para que o projeto pudesse se consolidar a partir das características da interdisciplinaridade e das necessidades apresentadas pelas instituições parceiras.

Desde 2019, o projeto conta com a participação de aproximadamente 60 acadêmicos, sendo 4 bolsistas e o restante voluntários, os quais advêm de 12 cursos de graduação da UCDB: Medicina Veterinária, Ciências Biológicas, Fisioterapia, Biomedicina, Pedagogia, Psicologia, Enfermagem, Jornalismo, Farmácia, Nutrição, Zootecnia e Agronomia.

Além dos acadêmicos, o projeto conta com uma equipe de docentes, formada por 1 professor coordenador e 4 professores colaboradores. Os docentes representam diferentes áreas do conhecimento, que são Biomedicina, Ciências Biológicas, Fisioterapia, Medicina Veterinária e Pedagogia, o que garante a multidisciplinaridade entre as áreas e a relação dialógica entre os diferentes campos do conhecimento. 
Nesse sentido, acreditamos que:

A interdisciplinaridade representa uma nova consciência da realidade, um novo pensar, que resulta em um ato de troca, de reciprocidade e integração entre áreas distintas de conhecimento. Visa à produção de novos conhecimentos e à resolução de problemas, de modo global e abrangente (PELEIAS et al., 2011, p. 508).

Vale também ressaltar que o trabalho interdisciplinar se torna uma das principais premissas da extensão universitária. Por meio da integração entre as diferentes áreas, é oportunizado que os sujeitos desenvolvam a dialogicidade, compartilhem saberes e trabalhem colaborativamente em prol de um objetivo comum, que é socializar conhecimentos e contribuir com o desenvolvimento da sociedade.

Além disso, a presença de diferentes campos do conhecimento em um mesmo projeto torna-se a premissa para um trabalho mais colaborativo, diversificado e enriquecedor para aqueles que fazem parte do trabalho, uma vez que estão inseridos em um processo constante de aprendizagem, através da troca de saberes que se estabelece.

Além disso, Boavida e Ponte (2002, p. 5) salientam que:

Apesar das dificuldades acrescidas que poderão surgir nestas equipes, elas têm, no entanto, a vantagem de possibilitar olhares múltiplos sobre uma mesma realidade, contribuindo, assim, para esboçar quadros interpretativos mais abrangentes para essa mesma realidade.

Nessa ótica, cabe também destacarmos que um dos principais benefícios oferecidos pela extensão universitária esteja na oportunidade que docentes e estudantes têm em ampliar não apenas os conhecimentos acadêmicos e científicos, mas ressignificarem seus saberes e percepções pessoais acerca da sociedade, do compromisso social, do papel que desempenham enquanto cidadãos e da relação e do trabalho em equipe que desempenham nos trabalhos extensionistas.

Ressaltamos também que a universidade tem como premissa atual superar a herança deixada pelos modelos de ensinos tradicionais, nos quais os professores se apresentavam como detentores do saber e os estudantes como sujeitos passivos do processo ensino e aprendizagem. Cabe aos professores e acadêmicos serem, hoje, coparticipantes do processo educativo, formando uma comunidade do saber, sendo juntos protagonistas do ato pedagógico, trocando saberes, compartilhando experiências e ampliando a visão de mundo e sociedade. 
Além disso, o envolvimento de professores e acadêmicos nas atividades extensionistas permite-lhes reconhecerem-se como sujeitos sociais e educativos, adotando práticas e posturas mais conscientes acerca de suas formações profissionais e cidadãs, passando a se perceberem como coparticipantes de um "mundo no qual podem contribuir com a indicação do sentido e da história da humanidade" (SÍVERES, 2013, p.23-24).

Ou seja, a universidade oferece a seus atores, através do trabalho extensionista, oportunidades de reflexões sobre seus papéis na sociedade, além de oportunizá-los a compreenderem que o ponto central da extensão, não é de apenas levar conhecimentos para as comunidades, como se elas fossem folhas em branco, mas sim de praticar a escuta e valorizar os saberes culturais das comunidades atendidas, os quais se tornam âncoras para nos ajudar a melhor compreender a sociedade e suas prerrogativas sociais, culturais, políticas e humanitárias.

Desse modo, o projeto de extensão "Saúde Pública em Ação" tem como principal objetivo compartilhar com a comunidade externa da UCDB conhecimentos acerca de saúde única, a fim de melhorar a qualidade de vida das pessoas, por meio de ações que envolvem aspectos voltados para a saúde humana, animal e cuidados com o meio ambiente, a partir de uma escuta efetiva e dos interesses próprios de cada comunidade atendida.

A interface entre a saúde humana, animal e ambiental, denominada de Saúde Única ("One Health"), se refere justamente à estreita relação existente entre a humanidade, os animais e o meio ambiente. É através desse conceito que os organismos de todo mundo podem planejar um conjunto de políticas públicas para prevenção e controle de enfermidades em todos os territórios. O desequilíbrio da tríade "ambiente - animal - humano" pode trazer sérias consequências para o ecossistema, incluindo pandemias (como a qual estamos vivenciando) e extinção de biomas.

Contudo, uma das principais premissas do projeto é realizar um diagnóstico de problemática em uma comunidade olhando não apenas para o problema principal e sim para todas as situações ao redor que podem contribuir indiretamente para a ocorrência daquela enfermidade, colocando em prática a Saúde Única.

As ações desenvolvidas pelo projeto "Saúde Pública em Ação" visam atender diferentes públicos, desde crianças, adolescentes, jovens, adultos e idosos. As ações ocorrem em diferentes regiões da cidade de Campo Grande, capital do estado de Mato Grosso do Sul, e até mesmo em outros municípios do Estado. O desenvolvimento do trabalho nas instituições parceiras se dá através de parcerias celebradas entre os seus representantes. 
Em 2020, o projeto firmou parceria e atendeu instituições como: Secretaria Municipal de Educação de Campo Grande (SEMED), projetos comunitários, Organização Não Governamentais (ONGs), Associações de bairros, Batalhão de Polícia Militar Ambiental (PMA), Instituto de Meio Ambiente de Mato Grosso do Sul (IMASUL), empresas veterinárias locais, grupos de escoteiros, escolas da rede privada de ensino de Campo Grande e de outros municípios.

A diversidade presente nas características dos públicos atendidos pelo projeto e a variedade nas ações desenvolvidas, permitem aos acadêmicos e professores que compõem o projeto, dialogarem multidisciplinarmente com a comunidade, entrando em contato com características culturais, sociais e econômicas diversificadas, aprimorando os aspectos de resiliência, humanidade, salesianidade e empatia com o próximo.

No que tange esse aspecto, Severino (2007, p. 32) considera que

[...] a extensão tem grande alcance pedagógico, levando o jovem estudante a vivenciar sua realidade social. É por meio dela que o sujeito/aprendiz irá formando sua nova consciência social. A extensão cria então um espaço de formação pedagógica, numa dimensão própria e insubstituível (SEVERINO, 2007, p. 32).

Como ações que vêm sendo desenvolvidas pelo projeto, podemos destacar a realização de palestras sobre diferentes problemáticas que envolvem a temática de saúde única, oficinas e capacitações para professores, pais e familiares das crianças atendidas pelas escolas parceiras, como por exemplo a realização de oficina de primeiros socorros.

Além disso, o projeto realiza vacinação antirrábica e desverminação de cães e gatos, além de campanhas de orientações acerca de prevenção e tratamento de doenças zoonóticas e epidemiológicas, orientações acerca de acidentes com animais peçonhentos e silvestres, orientações acerca de plantas tóxicas, orientação sobre higiene pessoal, IST's e realização de ações que envolvem a educação ambiental e ações lúdicas com as crianças, a partir das temáticas de saúde única. Algumas ações são realizadas até mesmo fora da cidade de Campo Grande, através de parcerias estabelecidas com prefeituras de outros municípios do Estado.

Além disso, o projeto conta com um laboratório, instalado nas dependências do Hospital Veterinário da UCDB, o qual é utilizado para preparação de materiais pedagógicos, orientativos e lúdicos a serem utilizados nas ações. O laboratório é também um espaço de visitação para estudantes das escolas da rede pública e privada, os quais, acompanhados pelos professores, são recebidos na UCDB para a realização do "Dia de Saúde Pública em Ação". 
Essa ação do projeto, a partir de uma parceria celebrada com a Secretaria Municipal de Educação de Campo Grande e com escolas da rede privada, oportunizou aos estudantes dos anos finais do ensino fundamental, além de conhecerem os espaços da universidade, terem a oportunidade de participarem de oficinas de primeiros socorros, com ênfase em desengasgo, receberem orientações sobre doenças zoonóticas, higiene pessoal e prevenção de acidentes com animais peçonhentos.

Ainda durante a programação, os estudantes visitantes, acompanhados pela equipe do projeto, têm a oportunidade de conhecer o biotério da UCDB, onde, além de receberem orientações sobre as diferentes espécies de animais que ali habitam, como jacarés, cágados, serpentes e roedores, são oportunizados a conhecerem os animais, ampliando seus saberes e estabelecendo uma relação com os conteúdos estudados na escola, por meio das vivências ali desenvolvidasi ${ }^{i}$.

Severino (2007) considera que a universidade contemporânea precisa desenvolver a experiência ativa do estudante, para que ele não tenha os conteúdos assimilados de modo passivo, mas que desenvolva condições de tornar-se crítico e atuante, tanto no contexto acadêmico como social. Tais aspectos são contemplados em ações como a do Dia de Saúde Pública, desenvolvida pelo projeto de extensão "Saúde Pública em Ação", onde professores e acadêmicos, juntos, atuam colaborativamente, de forma ativa, compartilhando com a comunidade os conhecimentos adquiridos na sala de aula.

Nessa prerrogativa, vale também destacar que são os acadêmicos integrantes do projeto, quem desenvolvem as oficinas, assim como realizam as orientações e os diálogos com o público atendido, sendo os docentes do projeto orientadores e mediadores desse processo, a fim de oportunizar um maior protagonismo aos acadêmicos.

Tais premissas vêm ao encontro do atual momento em que a sociedade se encontra, momento que exige flexibilidade, adaptações, busca de novos conhecimentos, de novas formas de desenvolver o ensino, de estabelecer relações e de ressignificar saberes e formas de aprendizagens.

\section{O contexto da pandemia e as readequações do Projeto de Extensão "Saúde Pública em Ação"}

A partir do dia 16 de março de 2020, a UCDB, ao considerar o cenário pandêmico que se avançava no país, em decorrência da COVID-19, resolve suspender as atividades de ensino, pesquisa e extensão de modo presencial e migrá-las para o modo remoto. Tendo em vista tal situação, fizeram-se necessárias diversas adequações nos planejamentos previstos para o desenvolvimento dos trabalhos na universidade, incluindo, assim, as atividades dos projetos e laboratórios de extensão, uma vez que as cargas horárias docentes destinadas aos projetos de extensão foram mantidas pela universidade, durante todo o período. 
Entendendo que a principal premissa da extensão universitária é desenvolver-se de forma direta e próxima das comunidades, fez-se necessário repensarmos os planejamentos e as ações previamente organizadas, a fim de podermos desenvolvê-las de modo remoto, respeitando a necessidade do distanciamento social, porém, mantendo o objetivo de compartilhar com a sociedade os conhecimentos produzidos no campo acadêmico.

Podemos dizer que esse exercício de mudança, num primeiro momento, não foi fácil, pois exigiu alterações de paradigmas e rompimentos de pensamentos já estabelecidos acerca das metodologias de trabalho que vinham sendo adotadas pelo projeto.

Desse modo, fizeram-se necessários muitos momentos de diálogos entre a equipe de docentes e acadêmicos, realização de estudos, trocas de ideias e desenvolvimento de pesquisas, para juntos, traçarmos um novo caminho e planejarmos a continuidade do projeto, a partir de então, sob um novo formato.

Há de ressaltar que um dos principais pontos a serem levados em consideração pela equipe foi a necessidade de ouvirmos as necessidades dos parceiros do projeto, para que as ações propostas tivessem, de fato, significados positivos e fossem ao encontro das necessidades apresentadas por cada comunidade atendida.

Silva (1997) sugere que a universidade, ao propor ações comunitárias, planeje e execute as atividades respeitando e não violando os saberes e culturas de cada público, pois o trabalho precisa ocorrer através da parceria, da escuta e da troca e não da imposição de saberes e de conhecimentos.

Nessa ótica, a partir do contato com os parceiros, reuniões e estudos desenvolvidos entre a equipe do projeto, os planos de trabalhos que haviam sido previstos para serem desenvolvidos presencialmente foram flexibilizados e alterados para serem desenvolvidos de modo remoto.

Como principais ações desenvolvidas pelo projeto no ano de 2020, neste novo formato exigido pela pandemia, podemos destacar a preparação e o envio de vídeos orientativos, folders e cartilhas aos parceiros por meio das redes sociais, os quais abordaram diferentes temáticas, como: higiene pessoal, formas de higienização correta dos pertences e objetos pessoais, higienezação e armazenamento correto de alimentos, vídeos de motivação, cuidados com a saúde física e mental, orientações acerca de cuidados físicos e posturais no trabalho remoto, hábitos alimentares saudáveis; além de dicas sobre prevenção, formas de combate e sintomas sobre outras doenças pandêmicas bastante presentes em nosso Estado, como Dengue, Chikungunya e Zikavirus.

Além disso, a partir do contato estabelecido com equipes gestoras das escolas parceiras, foram desenvolvidos materiais orientativos a partir de vídeos, folders e cartilhas acerca de temáticas contempladas no currículo escolar, os quais eram compartilhados com alunos e 
familiares por meio das redes sociais e aplicativos digitais adotados pelas escolas, a fim de contribuir com o processo de ensino e aprendizagem dos educandos.

Por meio de plataformas digitais, foram realizadas algumas capacitações com os acadêmicos participantes do projeto, envolvendo temáticas diversificadas que são contempladas nas ações do projeto, a exemplo de uma capacitação envolvendo a temática de gravação e edição de vídeos, uma vez que, diante desse novo cenário, muitos foram pegos de surpresa e não tinham conhecimento e domínio sobre o trabalho de gravar e editar vídeos.

Também foram desenvolvidas lives e webinar acerca de temáticas que envolvem problemáticas atuais e relevantes, tanto para a equipe do projeto como para os parceiros e outros estudantes e professores da universidade e da sociedade num contexto geral. Dentre as lives e webinar, foram abordados temas como cuidados com a saúde mental em tempos de pandemia. Ressalta-se que na webinar realizada se teve um alto número de participantes, assim como bastante interação do público com os palestrantes, mostrando a importância e a necessidade de se discutir tal problemática, num momento tão difícil e desafiador para todos.

Através da parceria desenvolvida com a Secretaria Municipal de Educação de Campo Grande, desenvolvemos formações continuadas, por meio de plataformas digitais, para as equipes das escolas de educação infantil. Tais formações foram desenvolvidas através de temas sugeridos pelas equipes, buscando, assim, aproximar os novos conhecimentos da realidade de cada instituição.

De acordo com Síveres (2013), esse tipo de ação formativa oportuniza a criação de uma rede de diálogos e saberes entre profissionais e instituições educacionais, facilitando o desenvolvimento de ações de cooperação e compartilhamentos de conhecimentos, os quais se constroem e se fortalecem através desse processo integrador entre os sujeitos. Para o autor, tal premissa possibilita ainda o fortalecimento da autonomia, da autoestima de professores e estudantes participantes desse processo, os quais passam a identificar a instituição como uma verdadeira "incubadora de saberes e conhecimentos" (SÍVERES, 2013, p. 23).

Nessa mesma ótica, Mello, Neto e Petrillo (2020, p. 19) pontuam que as ações extensionistas "possibilitam ao aluno uma vivência transformadora e significativa, uma vez que este se torna artífice da construção de uma formação compromissada com a sociedade".

Dentre os temas mais abordados nas formações, podemos destacar a questão da saúde da criança em tempos de pandemia, prevenção a acidentes domésticos, saúde única nas escolas, saúde do professor, além de discussões acerca da importância dos cuidados com o corpo e os movimentos das crianças, especialmente em tempos de pandemia, em que as crianças se encontram mais em casa, sem muitas atividades físicas e de interação com outras crianças. 
Acreditamos que as ações desenvolvidas ao longo de 2020, mesmo com tantos desafios, demonstram a importância da característica da flexibilidade, da escuta e da pesquisa dentro da extensão universitária, pois é a partir desses elementos que o trabalho poderá ser desenvolvido de modo eficaz e significativo.

Além disso, a extensão universitária não pode ficar presa a uma única forma de se desenvolver, precisa acompanhar as necessidades atuais da sociedade e, a partir disso, planejar e realizar ações que, de fato, tornem-se efetivas para a ascensão social, para a conquista da autonomia e melhoria da sociedade. Conforme sugerem Mello, Neto e Petrillo (2020, p. 20), "A construção do conhecimento não pode ficar insulada na universidade, senão deve ir ao encontro com possíveis soluções das reais necessidades que afligem a sociedade (efetivamente na solução de problemas sociais)" e esse é o efetivo papel da extensão universitária, inclusive em tempos de pandemia.

\section{Considerações finais}

A extensão universitária é um importante mecanismo de formação para os acadêmicos e docentes, ela possibilita que esses atores vivenciem diferentes realidades e ampliem seus conhecimentos acadêmicos, sociais e pessoais. Nessa ótica, a extensão também oportuniza que a universidade cumpra com seu dever social de partilhar os conhecimentos acadêmicos com a sociedade.

Assim, cabe aos envolvidos com o trabalho extensionista, primeiramente, entender a premissa da extensão universitária, sua relação com a sociedade e, a partir disso, buscar mecanismos que garantam o contato e a aproximação entre universidade e sociedade, especialmente neste momento de pandemia, o qual exige flexibilidade, busca por novos meios de contatos, interações, quebras de paradigmas e busca de acesso ao conhecimento, através de outras ferramentas, metodologias e possibilidades, oportunizando que esses conhecimentos não cheguem somente até a universidade, mas que principalmente por meio das veias extensionistas alcancem aqueles que não têm acesso e condições de frequentar uma cadeira acadêmica.

Esperamos que este trabalho possa suscitar novas discussões e ideias acerca de como desenvolver a extensão universitária, de modo a garantir a dialogicidade, a interdisciplinaridade e, especialmente, o contato efetivo com as comunidades externas às universidades, mesmo diante desse novo cenário pandêmico, mostrando ser possível romper muros, sairmos de nossas "caixas" e, a partir do diálogo, da troca, da escuta e da colaboração, somar forças, conhecimentos e lutar por uma sociedade mais igualitária, mais acessível e, sobretudo, mais humanitária. 


\section{Referências}

BOAVIDA, A. M.; PONTE, J. P. Investigação colaborativa: potencialidades e problemas. In: GTI (org.). Refletir e investigar sobre a prática profissional. Lisboa: APM, 2002. p. 43-55.

BRASIL. Constituição (1988). Constituição da República Federativa do Brasil. Brasília, DF: Senado Federal, 1988.

FREIRE, Paulo. Pedagogia do oprimido. 17. ed. Rio de Janeiro: Paz e Terra, 1987.

MELLO, C. de M.; NETO, J. R. M. de A.; PETRILLO, R. P. Curricularização da Extensão Universitária. Rio de Janeiro: Freire Bastos, 2020.

PELEIAS, I. R. et al. Interdisciplinaridade no Ensino Superior: análise da percepção de professores de controladoria em cursos de ciências contábeis na cidade de São Paulo. Avaliação, Campinas, SP, v. 16, n. 3, 2011. Disponível em: https://www.scielo.br/pdf/ aval/v16n3/v16n1a02 Acesso em: 08 maio 2020.

SEVERINO, A. J. Metodologia do trabalho científico. 23. ed. São Paulo: Cortez, 2007.

SÍVERES, L. O princípio da aprendizagem na extensão universitária. In: SÍVERES, L. (org.) A extensão universitária como um princípio de aprendizagem. Brasília: Liber Livro, 2013.

SILVA, O. D. da. O que é extensão universitária? Integração ensino, pesquisa, extensão, v.III, ano 9, 1997. Disponível em: http://www.ecientificocultural.com/ECC2/artigos/ oberdan9.html\#Rodapé Acesso em: 29 out. 2019.

UNIVERSIDADE CATÓLICA DOM BOSCO. Regimento Geral: Política de Extensão. Campo Grande-MS, 2018.

\footnotetext{
Notas

${ }^{i}$ Ressalta-se que essa ação se desenvolveu no ano de 2019, não sendo possível desenvolvê-la em 2020, por conta da pandemia.
} 